\title{
A Dual-band Planar Antenna for Wireless Local Area Network Applications
}

\author{
Yasser A. Fadhel* \\ Department of Electrical and Computer Engineering, University of Duhok, Duhok, Iraq
}

\section{${ }^{*}$ Corresponding author: \\ Yasser A. Fadhel, \\ Department of Electrical \\ and Computer Engineering, \\ University of Duhok \\ Duhok, Iraq. \\ E-mail: yasser.fadhel@uod.ac}

\author{
Received: 01 August 2019 \\ Accepted: 03 September 2019 \\ Published: 01 December \\ 2019 \\ DOI \\ 10.25156/pti.v9n2y2019.pp105-111
}

\section{A B S T R A C T}

Wireless local area network (WLAN) communication is one of the fast and secure wireless technologies, which is vastly used in nowadays portable and handheld devices. This paper is oriented on designing of a planar WLAN antenna to serve in WLAN network devices. The designed antennas are single and dual-band planar monopole antennas to be working at IEEE 802.11 WLAN frequencies; $2.45 \mathrm{GHz}$ and $5.2 / 5.8 \mathrm{GHz}$ bands. Different configurations have been used in the design process, especially for the dual-band antenna, where dual-resonant is required. The antennas have been designed analytically then simulated using the CST software package. Simulation results for the input reflection coefficient, realized gain, and radiation pattern have been considered to evaluate their features. The antennas have also been fabricated practically and practical measurements for the input reflection coefficient and radiation pattern have been taken which shown a good agreement with those of simulation.

Keywords: Dual-band; IEEE 802.11; Planar square monopole antenna; Rhombic monopole antenna; Wireless local area network planar antennas

\section{INTRODUCTION}

The rapid modification and vast variety of nowadays different wireless communication devices attracted researchers to design multiband antennas which are compatible with their frequency ranges. Microstrip planar antennas are preferred in the design of major wireless communication devices due to their low cost, lightweight, and low profile; also their ease of fabrication and could be compacted within these devices with no external parts. Researchers have competed in selecting different shapes for their designs, and one of the most essential shapes is the rectangular or square shape monopole antenna. The planar square monopole antenna (PSMA) has two configurations PSMA1 and PSMA2 depending on whether being fed from one of its sides or corners as suggested by Ray (2008). Some rectangular shape antennas have been designed either to be working at single frequency as done by Evans et al. (2004), dual-band as by Puskely et al. (2016), that by Basaran and Sertel (2015), and multiband as that by Wu et al. (2016) which composed of three rectangular tuning strips, or broadband range of frequencies, as designed by Ullah and Tahir (2018).

Due to the simplicity of the square shape, it is supposed to be working at limited frequency bands. Nevertheless, some researchers tried to improve its performance by modifying its feeding like done by Ray et al. (2009), or through applying the fractal technique on it which leads to broadening its impedance bandwidth as done by Sayidmarie and Fadhel, (2011). Square ring shape has also attracted some designers, in which good results have been acquired as by Puskely et al. (2016), and even it enables occupying the entire ultra-wideband frequency range as done by Deng et al. (2008) and that done by Gorla and Harackiewicz (2016). The rhombic patch could be considered to be a square shape antenna being fed from one of its vertex, as done by Mahatthanajatuphat et al. (2009), when they succeeded to introduce a multiband planar antenna to be used for Universal Mobile Telecommunications System, wireless local area network (WLAN), and mobile WiMAX applications but on the cost of some complicated modification of Minkowski fractal geometry.

In this paper, a simple square shape planar antenna has been designed with different configurations to get single- and dual-band of operation to be serving at WLAN bands $2.45 \mathrm{GHz}(2.4-2.484)$ and 5.2/5.8 GHz (5.15-5.35 GHz/5.725-5.825 GHz). But actually, for the design at a higher band, the importance will be given to the frequency $5.5 \mathrm{GHz}$ as a middle value of the higher band. The designed antennas have been simulated using CST Microwave Studio ${ }^{\circledR} 2014$ commercial software package, and different simulated results have been acquired. To validate the design ideas, all of the proposed antennas have been fabricated and practical measurements have 
been taken using Rohde and Schwarz ${ }^{\circledR}$ ZVL13 Vector Network Analyzer (VNA), and the good agreement between the simulated and measured results has confirmed the validation of the design.

\section{ANTENNA DESIGN}

A simple planar antenna with square shape has been designed. It is desired to be utilized for WLAN applications, a PSMA has been designed at certain narrow bands of frequency. The design has been performed on single and double bands of frequencies, as follow:

\section{Single Band PSMA1}

The geometry of this antenna is illustrated in Figure 1 and it has been simulated assuming a dielectric FR4 substrate of $1.6 \mathrm{~mm}$ thickness, the relative permittivity of 4.3 with dielectric loss tangent of 0.025 . The first resonant frequency is determined by a formula suggested by Ray (2008) which said:

$$
f_{L}=\frac{c}{\lambda}=\frac{7.2}{(L+r+P) * k} G H z
$$

where $f_{\mathrm{L}}$ is the lower band-edge frequency, $P$ is the length of the $50 \Omega$ feed line in $\mathrm{cm}$, which has been optimized by trial and error for this design. And the values of $L$ and $r$ of the equivalent cylindrical monopole antenna for PSMA with a side length of $S$ are given by Ray (2008) as:

$$
\begin{gathered}
L=S, \text { and } r=\frac{S}{2 \pi}, \text { for PSMA1 } \\
L=\sqrt{2} S, \text { and } r=\frac{S}{2 \sqrt{2} \pi}, \text { for PSMA2 }
\end{gathered}
$$

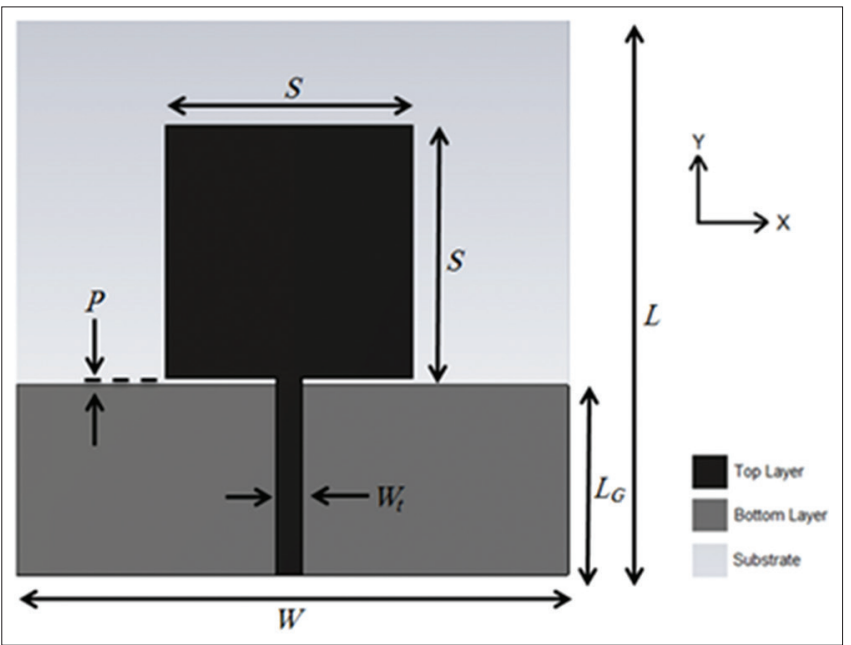

Figure 1: Geometry of single-band planar square monopole antenna 1 antenna where PSMA1 and PSMA2 are two possible configurations, as shown in Figure 2, while $k=\sqrt{\varepsilon_{e f f}}$ and the approximated value of $\varepsilon_{\text {eff }}$ is given by Balanis (2005):

$$
\varepsilon_{e f f} \approx \frac{\varepsilon_{r}+1}{2}
$$

In this paper, the substrate FR4 has been used with $\varepsilon_{\mathrm{r}}=4.3$ and thickness of $1.6 \mathrm{~mm}$, accordingly equation (4) will give $\varepsilon_{\text {eff }}=2.65$; as a result, $k$ will be 1.627 , but as an empirical value, it has been suggested by Ray (2008) to be taken 1.15. Therefore, if the lower frequency $f_{\mathrm{L}}$ is chosen to be $5.5 \mathrm{GHz}, k=1.15$ and $P=0.5 \mathrm{~mm}=0.05 \mathrm{~cm}$, then for PSMA1 equation (2) has been substituted in (1) and the value of $S$ will be accordingly equal to $9.38 \mathrm{~mm}$, and for $f_{L}=5.5 \mathrm{GHz}, S$ will be $9.38 \mathrm{~mm}$.

Repeat for $f_{L}=2.45 \mathrm{GHz}$ this gives $S=21.6 \mathrm{~mm}$. However, for shifting the resonant frequency to $2.45 \mathrm{GHz}$, it is required to use a larger value of $S$. Therefore, $S=25 \mathrm{~mm}$ has been used. $P$ has been optimized again to be equal to $0.75 \mathrm{~mm}$. Then, further optimization has been performed on $P=0.1 \mathrm{~mm}$.

The ground plane has a length of $L_{G}$ which has been suggested to be equal to:

$$
L_{G}=\frac{\lambda_{e f f}}{4}=\frac{\lambda}{4 k}=\frac{c}{4 k f_{L}} G H z
$$

Where $\lambda_{e f f}$ is the effective wavelength at the desired frequency, and accordingly, $L_{G}$ at $2.45 \mathrm{GHz}$ is equal to $18.8 \mathrm{~mm}$.

The microstrip line width has been calculated from the following equation by Wadell (1991) and Wheeler (1977):

$$
Z_{o}=\frac{87}{\sqrt{\varepsilon_{r}+1.41}} \ln \left(\frac{5.98 \mathrm{~h}}{0.8 W_{\text {StrL }}+t}\right)
$$

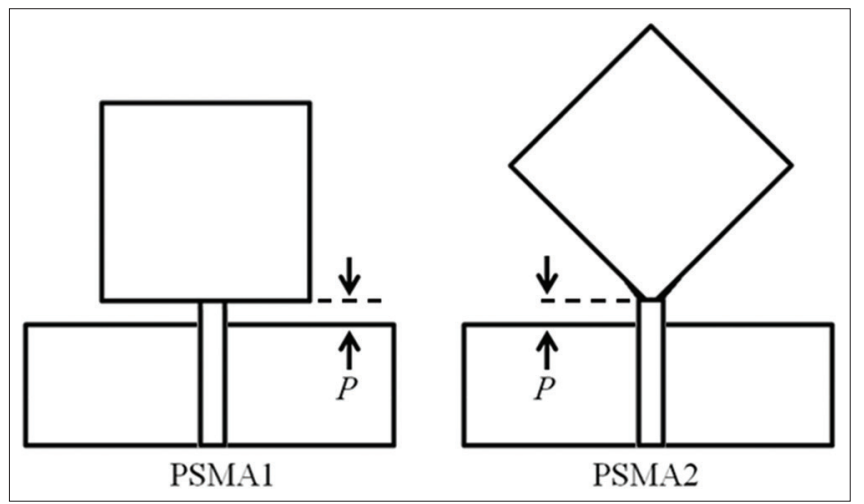

Figure 2: Various regular-shaped planar square monopole antennas with different feed configurations from Ray (2008) 
Where $b$ is the thickness of the substrate which is $1.6 \mathrm{~mm}$ as a typical value, $t$ is the metallization thickness which is $0.035 \mathrm{~mm}, Z_{\mathrm{o}}$ is the characteristic impedance for the microstrip line, $W_{\text {strL }}$ is the width of the microstrip feed line, and $\varepsilon_{r}$ is 4.3 for FR4 substrate. Therefore, to get $Z_{\mathrm{o}}$ equal to $50 \Omega$ then $W_{\text {str } \mathrm{L}}$ must be equal to $3 \mathrm{~mm}$ but further optimization has been done on this dimension to be equal to $2.5 \mathrm{~mm}$ in all antennas designed here, and for simplicity, $W_{S t r L}$ has been named $W_{t}$ in Figure 1 . The aforementioned and other optimized design parameters are shown in Table 1.

The single band antenna of PSMA1 shape configuration has been designed for two frequencies $2.45 \mathrm{GHz}$ and 5.5 $\mathrm{GHz}$. The design parameters of both single-band antennas are shown in Table 1.

\section{Dual-Band PSMA2}

A dual-band of PSMA2 configuration has been designed at two frequency bands of 2.45 and $5.5 \mathrm{GHz}$, as shown in Figure 3. This time PSMA2 configuration has been used for this design by adding a square slot inside the radiating patch to get two resonating square edges, unlike having one edge as that by Ray (2008) but the same formulas have been used for calculating the dimensions. Therefore, according to equations (1) and (3), $S$ is equal to 13.9 and $6.04 \mathrm{~mm}$ for the frequencies 2.45 and $5.5 \mathrm{GHz}$, respectively. But unfortunately, these dimensions are not working properly and do not satisfy the desired results. However, instead of that, it has been suggested that $S$ will be calculated according to equation (5) (i.e. $S=\lambda_{\text {eff }} / 4$ ) such as to resonate with each dimension with its frequency so that the dimensions were calculated to be $\left(S_{1}=18.8\right)$ and $\left(S_{2}=8.37 \mathrm{~mm}\right)$, as depicted in Table 1 .

\section{RESULTS AND DISCUSSION}

Simulation has been performed on the three designed antennas using the software package CST Microwave Studio ${ }^{\circledR}$ 2014. The reflection coefficient or input reflection coefficient

Table 1: Design parameters of the two-single band PSMA1 antennas and the dual-band PSMA2 antenna

\begin{tabular}{lccc}
\hline Parameters & \multicolumn{2}{c}{ Single-band PSMA1 } & Dual-band PSMA2 \\
\hline$f(\mathrm{GHz})$ & 2.45 & 5.5 & 2.45 and 5.5 \\
Dimensions (mm) & & & \\
$\mathrm{S}$ (Equs 1 and 2) & 21.6 & 9.38 & Non \\
$\mathrm{S}_{1}$ (Equs 1 and 3) & Non & Non & 18.8 \\
$\mathrm{~S}_{2}$ (Equs 1 and 3) & Non & Non & 8.37 \\
$\mathrm{~L}$ (Opt. ${ }^{*}$ ) & 55 & 23 & 48 \\
$\mathrm{~L}_{\mathrm{G}}$ (Equ. 5) & 18.8 & 8.37 & 18.8 \\
$\mathrm{P}$ (Opt.) & 0.75 & 0.1 & 0.25 \\
$\mathrm{~W}$ (Opt.) & 70 & 35 & 46 \\
$\mathrm{~W}_{\mathrm{t}}$ (Opt.) & 2.5 & 2.5 & 2.5 \\
\hline
\end{tabular}

Opt.*: Optimized. PSMA: Planar square monopole antenna curves for the all designed antennas have been plotted against frequency, as in Figure 4; it is obvious that each of the singleband antennas is resonating at their desired frequencies 2.45 and $5.5 \mathrm{GHz}$, while the dual-band antenna exhibits dualresonant on both aforementioned frequencies. These dips in the input reflection coefficient curves which occurred at the resonating frequencies have been validated by the realized gain curves, as shown in Figure 5. That figure shows peaks at those frequencies and almost the gain for all of these antennas is not $<2 \mathrm{~dB}$ at their working frequency bands which is comparable to that of the dipole antenna. Furthermore, the value of realized gain is doubled at $5.5 \mathrm{GHz}$ for dual-band antenna PSMA2 and jumped from 2 to more than $4 \mathrm{~dB}$.

After completion of the design and simulation for all of these antennas, the fabrication process started in Microwave

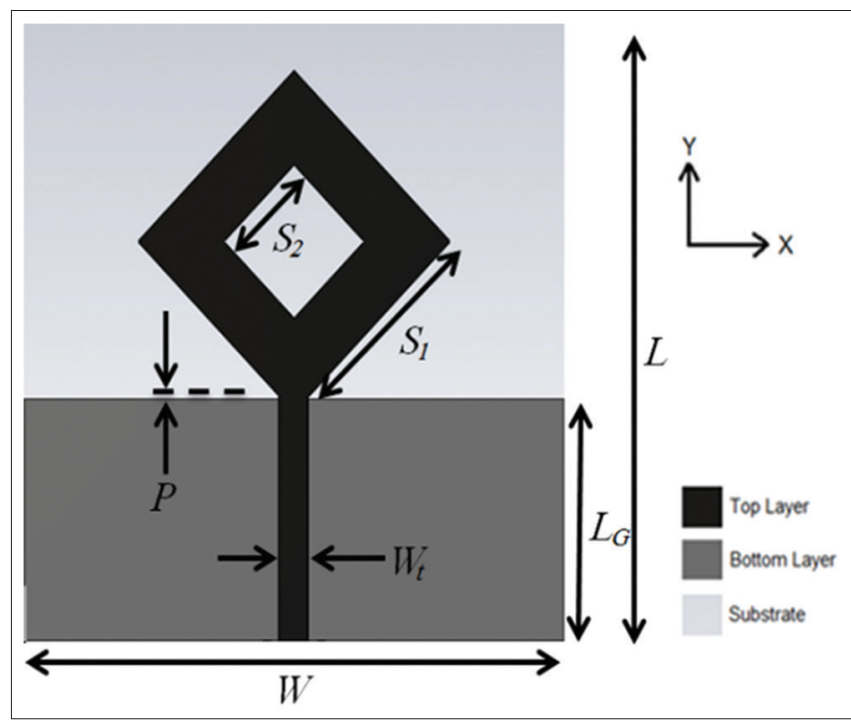

Figure 3: Geometry of dual band planar square monopole antenna 2 antenna

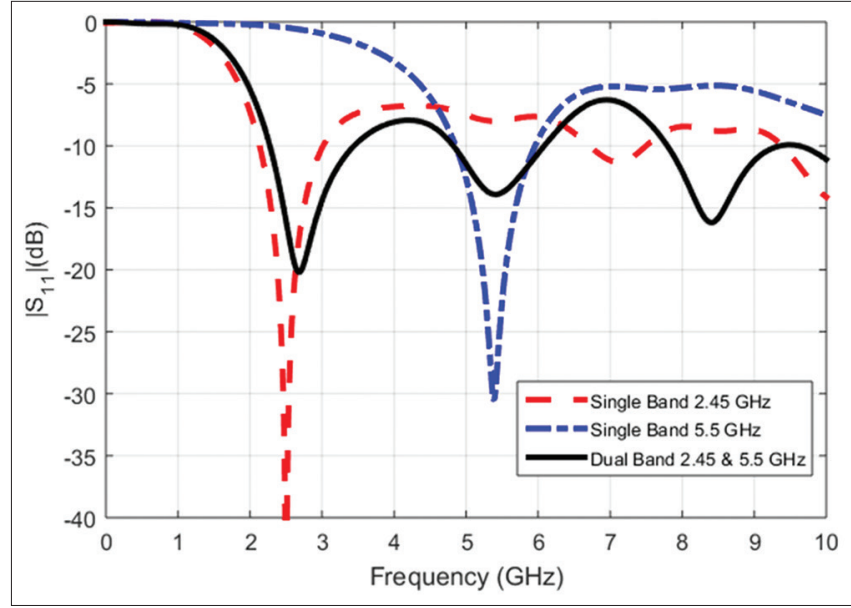

Figure 4: Input reflection coefficient curves for the two-single band planar square monopole antenna (PSMA1) antennas, and the dual-band PSMA2 antenna 
Engineering Laboratory in Electronics and Communication Engineering Department of University of Duhok. The substrate FR4 has been used as a printed circuit board and fabricated, as shown in Figures 6-8. The VNA Rohde and Schwarz ${ }^{\circledR}$ ZVL13 with a frequency range of $9 \mathrm{kHz} \sim 13.6$ $\mathrm{GHz}$ has been used for practical measurements, as shown in Figure 9. Validation of Figure 4 has been done through measuring the input reflection coefficient parameter for all fabricated antennas and compared with simulated results, as shown in Figures 10-12. These figures show good agreement between the practical and simulation results, which validating their designs.

The measurement set up shown in Figure 13 has been used for the radiation patterns measurements of the fabricated antennas. Practical measurements have been taken for the azimuthal (H-plane) radiation patterns and compared with those acquired from the simulation,

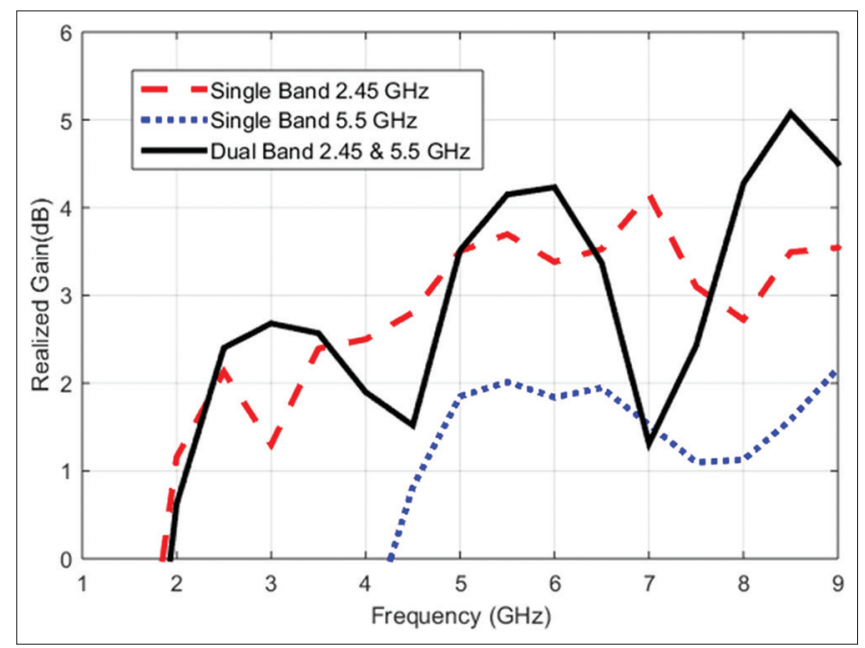

Figure 5: Realized gain curves for the two single-band planar square monopole antenna (PSMA1) antennas, and the dual-band PSMA2 antenna

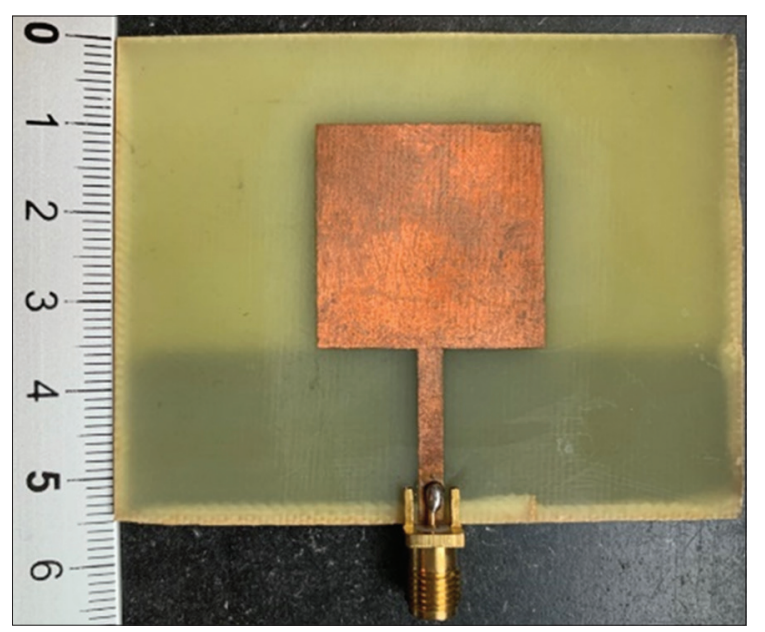

Figure 6: Fabricated single-band planar square monopole antenna 1 antenna at $2.45 \mathrm{GHz}$ as shown in Figures 14-16. The practical measured and simulated radiation patterns are almost meet each other in being omnidirectional patterns. The study of the simulated

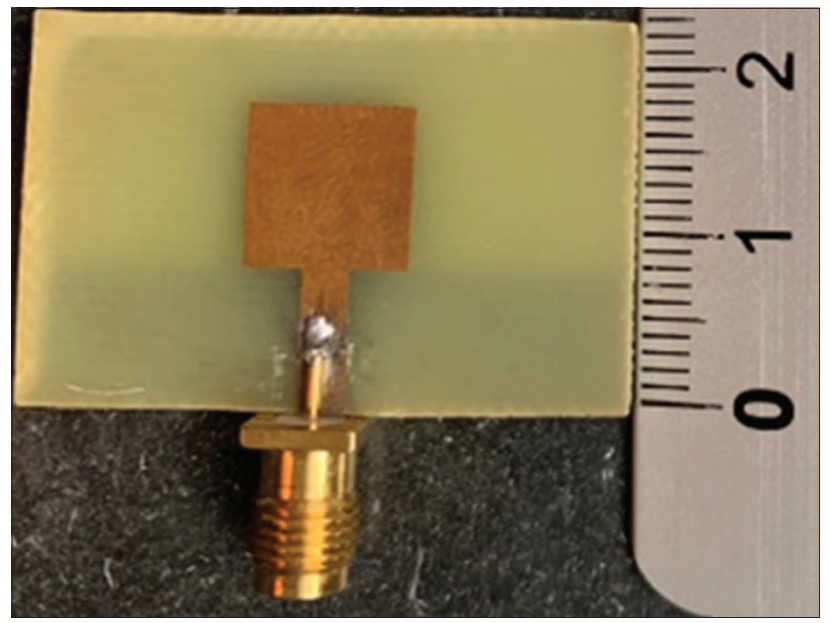

Figure 7: Fabricated single-band planar square monopole antenna 1 antenna at $5.5 \mathrm{GHz}$

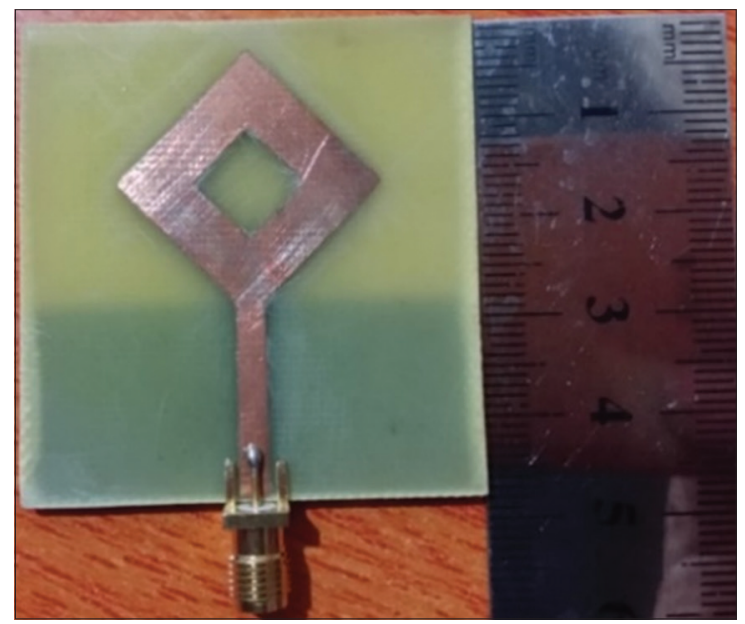

Figure 8: Fabricated dual-band planar square monopole antenna 2 antenna at 2.45 and $5.5 \mathrm{GHz}$

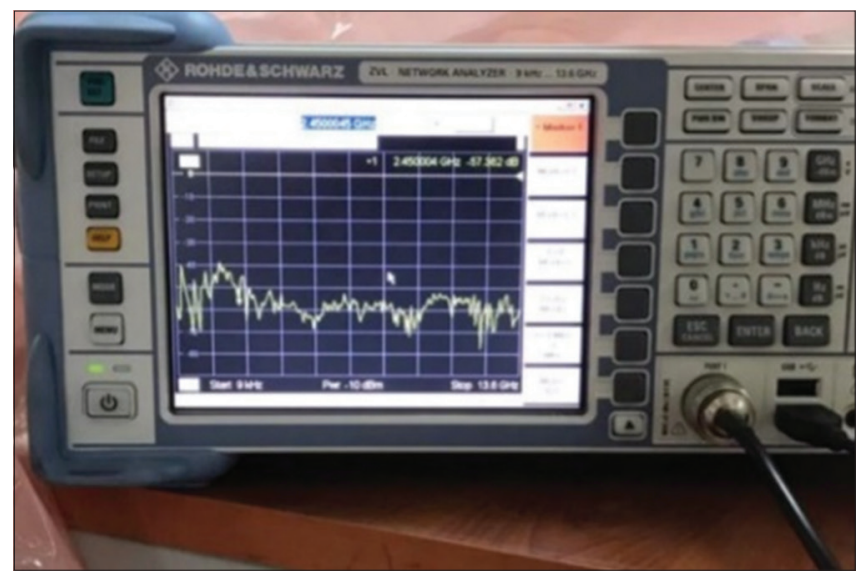

Figure 9: The vector network analyzer Rohde and Schwarz ${ }^{\circledR}$ ZVL13 with a frequency range of $9 \mathrm{kHz} \sim 13.6 \mathrm{GHz}$ 


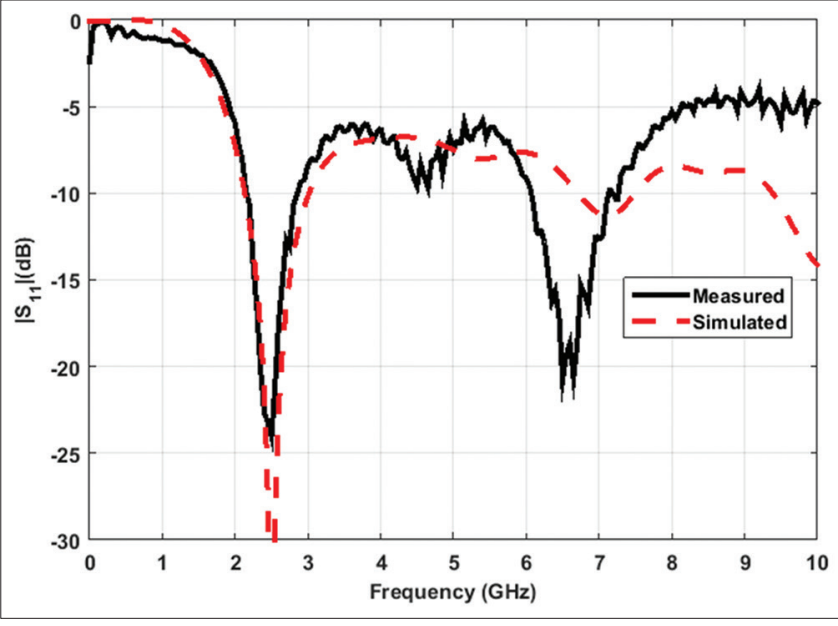

Figure 10: Measured and simulated input reflection coefficient curves for single-band planar square monopole antenna 1 antenna at $2.45 \mathrm{GHz}$

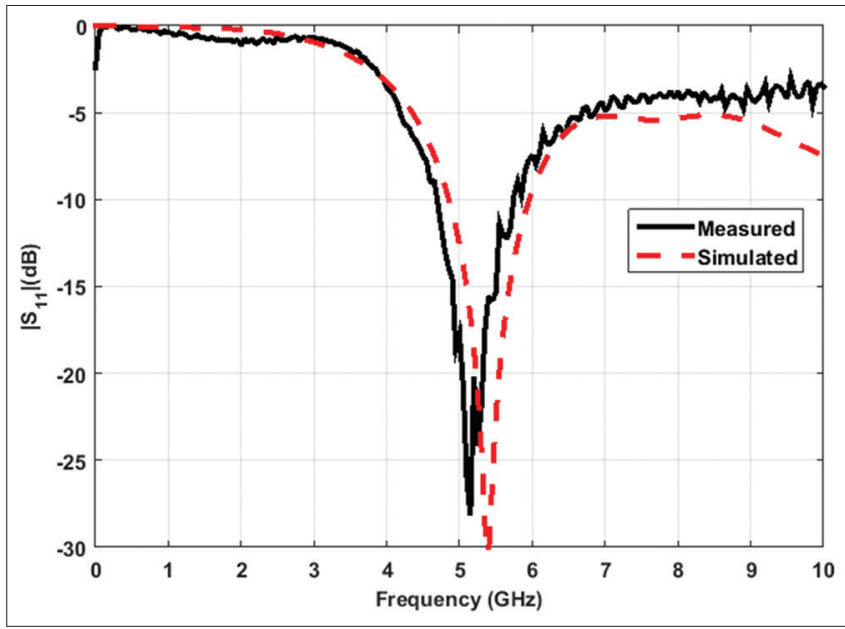

Figure 11: Measured and simulated input reflection coefficient curves for single-band planar square monopole antenna 1 antenna at $5.5 \mathrm{GHz}$

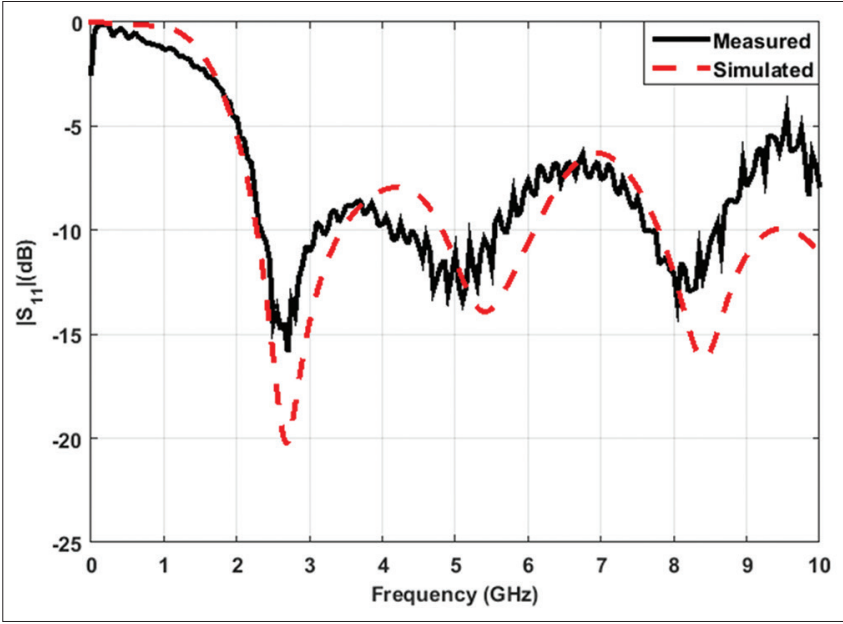

Figure 12: Measured and simulated input reflection coefficient curves for dual-band planar square monopole antenna 2 antenna at 2.45 and $5.5 \mathrm{GHz}$

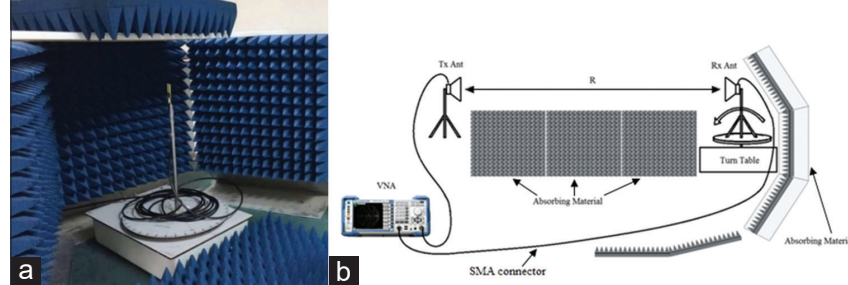

Figure 13: The measurement setup, (a) perspective view, (b) layout view

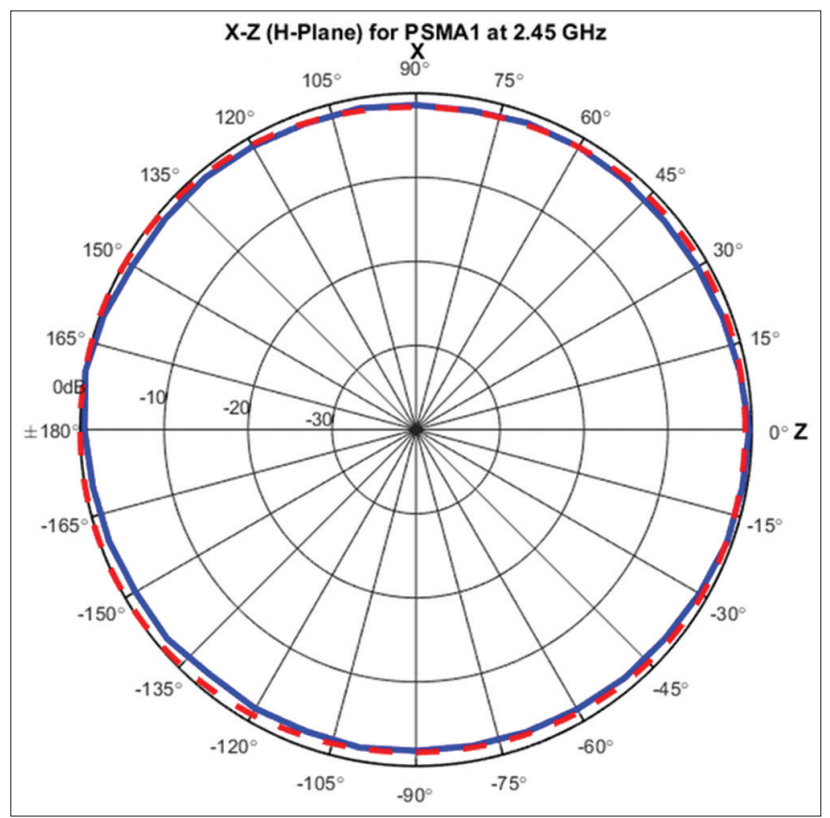

Figure 14: Measured (-) and simulated (- --$)$ azimuthal radiation patterns for single-band planar square monopole antenna 1 antenna at $2.45 \mathrm{GHz}$

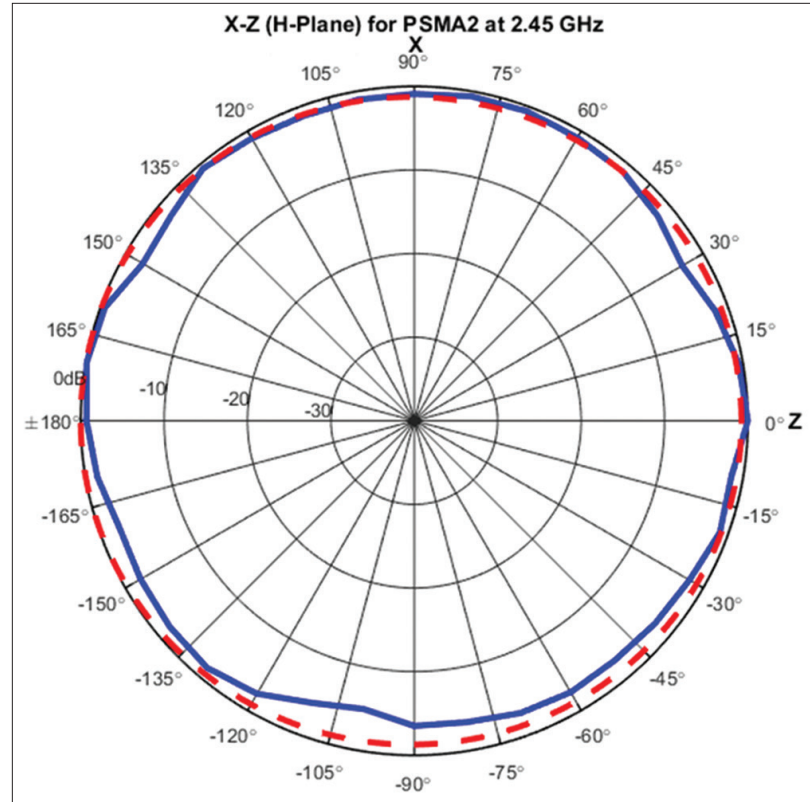

Figure 15: Measured (-) and simulated $(---)$ azimuthal radiation patterns for dual-band planar square monopole antenna 2 antenna at $2.45 \mathrm{GHz}$ 
surface current distribution for the three designed antennas, as depicted in Figures 17-19, shows the effectiveness of the radiating structure shape and size on the resonating frequencies that planned to be serving.

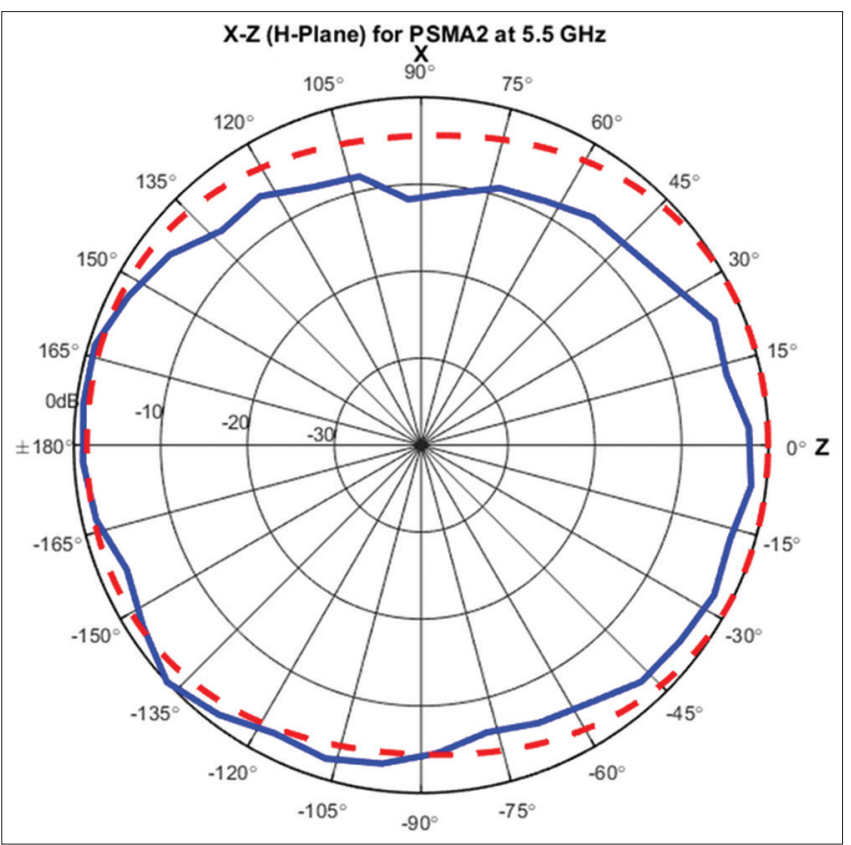

Figure 16: Measured (-) and simulated (- - -) azimuthal radiation patterns for dual-band planar square monopole antenna 2 antenna at $5.5 \mathrm{GHz}$
In comparison with the previous works like that by Ray (2008) and the other by Puskely et al. (2016), in this paper, the resonant frequency formula has been employed on two edges; inner and outer of the radiating square plane to get a dual-band of resonating. Furthermore, the slot added here has an advantage of adding the second higher resonant at $5.5 \mathrm{GHz}$, unlike other researches whom tried to widen the working band of their antennas at $2.45 \mathrm{GHz}$, through modifying its feeding as done by Ray et al. (2009) or adding a slots to its square monopole radiating plane as done by Evans et al. (2004).

\section{CONCLUSIONS}

The ease of design of PSMA antennas for WLAN frequency bands has been demonstrated. Dual bands of working are also performed through simple modifications of adding a slot which enables the second resonating. PSMA2 geometry configuration offers two inner and outer edges for the radiating patch; the inner edge length is smaller and resonating at higher frequency $5.5 \mathrm{GHz}$ and the outer edge length is larger which resonates at lower frequency $2.45 \mathrm{GHz}$. Simulation results are shown these resonations in the dips of the input reflection coefficient and the peaks of realized gain curves versus frequency. The fabrication of the designed antennas and the practical measurements of the input reflection coefficient and
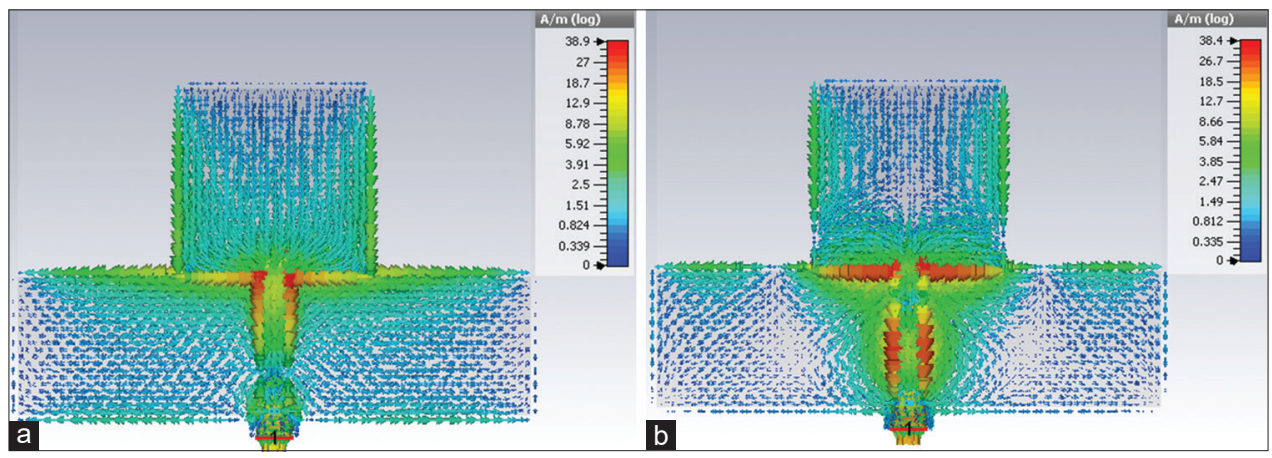

Figure 17: Surface current distribution for single-band planar square monopole antenna 1 antenna at $2.45 \mathrm{GHz}$, plotted for (a) 2.45 and (b) $5.5 \mathrm{GHz}$
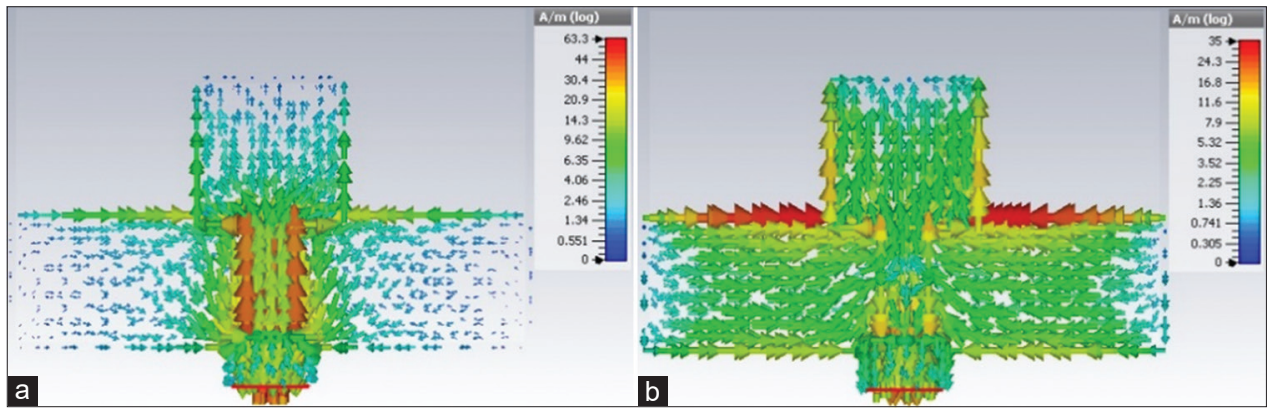

Figure 18: Surface current distribution for single-band planar square monopole antenna 1 antenna at $5.5 \mathrm{GHz}$, plotted for (a) $2.45 \mathrm{GHz}$ (b) $5.5 \mathrm{GHz}$ 

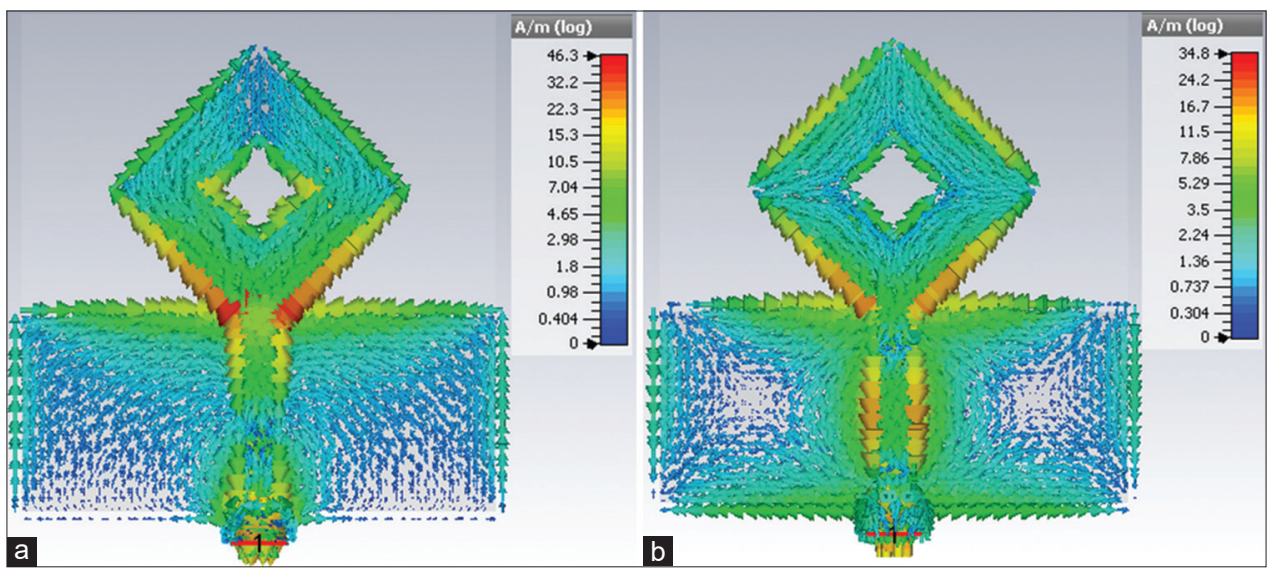

Figure 19: Surface current distribution for dual-band planar square monopole antenna 2 antenna, plotted for (a) $2.45 \mathrm{GHz}$, (b) $5.5 \mathrm{GHz}$

radiation pattern are shown good agreement with simulated results which validates their designs.

\section{REFERENCES}

Balanis, C. A. 2005. Antenna Theory Analysis and Design. $3^{\text {rd }}$ ed. John Wiley and Sons Inc., Hoboken, New Jersey. p817.

Basaran, S. C. and K. Sertel. 2015. Compact and planar monopole antenna for WLAN and WiMAX applications. Appl. Comput. Electromagn. Soc. J. 30(5): 546-550.

Deng, H., X. He, B. Yao and Y. Zhou. 2008. A Compact SquareRing Printed Monopole Ultra Wideband Antenna, ICMMT 2008 Proceedings. p1644-1646.

Evans, J. A., F. L. Lerma and M. I. Ammann. 2004. Printed Planar Monopole Antenna with Electromagnetically Coupled, High Frequency Postgraduate Student Colloquium, 6-7 Sep.

Gorla, H. R. and F. J. Harackiewicz. 2016. A novel rectangular ring planar monopole antennas for ultra-wideband applications. Prog. Electromagn. Res. C. 61: 65-73.

Mahatthanajatuphat, C., S. Saleekaw and P. Akkaraekthalin. 2009. A rhombic patch monopole antenna with modified minkowski fractal geometry for UMTS, WLAN, and mobile WiMAX application. Prog. Electromagn. Res. 89: 57-74.

Puskely, J., A. G. Yarovoy and A. G. Roederer. 2016. Two-port Dual- band Microstrip Square-ring Antenna for Radar Applications, $10^{\text {th }}$ European Conference on Antennas and Propagation (EuCAP).

Ray K. P. 2008. Design aspects of printed monopole antennas for UWB applications. Int. J. Antennas Propag. 2008: 1-8.

Ray, K. P., S. S. Thakur and R. A. Deshmukh. 2009. Broadbanding a Printed Rectangular Monopole Antenna, Applied Electromagnetics Conference (AEMC), 14-16 Dec. 2009. SAMEER, Mumbai, India. p1-4.

Sayidmarie, K. H. and Y. A. Fadhel. 2011. UWB Fractal Monopoles of Rectangular and Triangular Shapes, Proceeding of MAPE2011, 1-3 Nov. 2011, Beijing, China. p709-712.

Ullah, H. and F. A. Tahir. 2018. A Broadband Planar Rhombus Monopole Antenna for $28 \mathrm{GHz}$ Millimeter-Wave Communications, $12^{\text {th }}$ European Conference on Antennas and Propagation (EuCAP 2018), Jan.

Wadell, B. C. 1991. Transmission Line Design Handbook. Artech House, Norwood, MA.

Wheeler, H. A. 1977. Transmission-line properties of a strip on a dielectric sheet on a plane. IEEE Tran. Microw. Theory Tech. 25: 631-647.

Wu, L., J. Huang and N. Yuan. 2016. Compact Multiband Monopole Antenna for GPS/WLAN/WiMAX Application, IEEE International Conference on Microwave and Millimeter Wave Technology (ICMMT), 5-8 Jun. 